\author{
Marquette University \\ e-Publications@Marquette
}

$12-2004$

\title{
A TGA/FTIR and Mass Spectral Study on the Thermal Degradation of Bisphenol A Polycarbonate
}

Bok Nam Jang

Marquette University

Charles A. Wilkie

Marquette University, charles.wilkie@marquette.edu

Follow this and additional works at: https://epublications.marquette.edu/chem_fac

Part of the Chemistry Commons

\section{Recommended Citation}

Jang, Bok Nam and Wilkie, Charles A., "A TGA/FTIR and Mass Spectral Study on the Thermal Degradation of Bisphenol A Polycarbonate" (2004). Chemistry Faculty Research and Publications. 141.

https://epublications.marquette.edu/chem_fac/141 
Marquette University

e-Publications@Marquette

\title{
Chemistry Faculty Research and Publications/College of Arts and Sciences
}

This paper is NOT THE PUBLISHED VERSION; but the author's final, peer-reviewed manuscript. The published version may be accessed by following the link in th citation below.

Polymer Degradation and Stability, Vol. 86, No. 3 (December 2004): 419-430. DOI. This article is (C) Elsevier and permission has been granted for this version to appear in e-Publications@Marquette. Elsevier does not grant permission for this article to be further copied/distributed or hosted elsewhere without the express permission from Elsevier.

\section{A TGA/FTIR and Mass Spectral Study on the Thermal Degradation of Bisphenol A Polycarbonate}

\author{
Bok Nam Jang \\ Department of Chemistry, Marquette University, Milwaukee, WI \\ Charles A. Wilkie \\ Department of Chemistry, Marquette University, Milwaukee, WI
}

\begin{abstract}
The thermal degradation of polycarbonate under nitrogen was studied using TGA/FTIR, GC/MS and LC/MS as a function of mass loss. The gases evolved during degradation were inspected by in situ FTIR and then the evolved products were collected and analysed using FTIR, GC-MS and LC-MS. The structures of the evolved products are assigned on the basis of FTIR and GC/MS results. The main thermal degradation pathways follow chain scission of the isopropylidene linkage, and hydrolysis/alcoholysis and rearrangement of carbonate linkages. In the case of chain scission, it was proposed that methyl scission of isopropylidene occurs first, according to the bond dissociation energies. The presence of carbonate structures, 1,1'-bis(4-hydroxyl phenyl) ethane and bisphenol A in significant amounts, supports the view that chain scission and hydrolysis/alcoholysis are the main degradation pathways for the formation of the evolved products.
\end{abstract}




\section{Keywords}

Polycarbonate, Bisphenol A, Thermal degradation

\section{Introduction}

Polycarbonate (PC), mainly bisphenol A polycarbonate, shows very good physical and chemical properties, such as excellent transparency, high mechanical strength, good thermal stability and high heat distortion temperature. In addition, PC shows a high limiting oxygen index (LOI), 27, and produces a large fraction of char upon combustion [1]. Thus, polycarbonate and its blend with acrylonitrile-butadiene-styrene (ABS) exhibit effective flame retardant properties upon the addition of conventional halogen and/or non-halogen flame retardant agents, and these are widely used in electrical appliances. However, as the PC content in PC/ABS blends is decreased, its fire retardant performance with halogen-free fire retarding agents, such as triphenylphosphate (TPP) and resorcinolbis(diphenylphosphate) (RDP), is also decreased [2] [3]. It is thought that these results relate to the degradation characteristics of polycarbonate, so, understanding the degradation behaviour of polycarbonate is necessary in order to understand the action of the fire retardants.

Lee investigated the thermal degradation of PC under vacuum and in an oxygen atmosphere. He proposed that the initial step is oxidative hydrogen cleavage from isopropylidene linkage, followed by hydrolysis and alcoholysis of the carbonate. Various evolved products were assigned up to molecular weight of 228 using mass spectroscopy, MS. He explained that the degradation pathway follows chain scission as shown in (A) and (B) of $\underline{\text { Scheme } 1^{[4]}}$

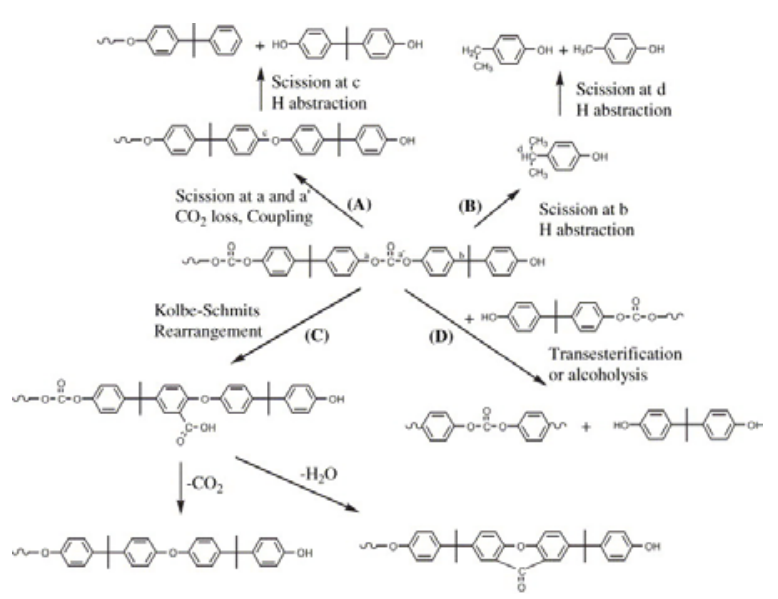

Scheme 1.

Davis et al. detected $\mathrm{CO}_{2}$, phenol and bisphenol $\mathrm{A}$ as the main volatile products, together with a small amount of $\mathrm{CO}$, alkyl phenol and diphenyl carbonate. They speculated that the carbonate group undergoes rearrangements, followed by hydrolysis and alcoholysis, as shown in (C) and (D) of Scheme 1; they also proposed the formation of the xanthone unit during thermal degradation of $P C[5],[6],[7]$.

McNeill et al. studied the thermal degradation mechanism of PC using thermal volatilisation analysis (TVA) under nitrogen. They detected and assigned some cyclic oligomers of bisphenol A carbonate and various phenol structures having masses of less than 228 using gas chromatography with a mass detector, GC/MS, and suggested a homolytic chain scission mechanism for the degradation of PC [8], [9].

Montaudo et al. carried out an extensive study on the degradation of polycarbonate with pyrolysisGC/MS [10], [11], direct pyrolysis mass spectral (DPMS) measurements ${ }^{[12]}$ and MALDI-TOF investigations [13], [14], 115], [16]. In the PGC/MS and DPMS study, they assigned xanthone units as well as cyclic oligomers and proposed that the major degradation pathways for $\mathrm{PC}$ are the rearrangement of carbonate 
linkage by intramolecular ester exchange and disproportionation of isopropylidene linkages. Recently, they carried out a MALDI-TOF investigation on the soluble fraction of solid residues of degraded PC samples and confirmed the existence of the xanthone structures in the degraded products.

Tsuge et al. characterised branching and/or cross-linked structures for PC by reactive pyrolysis-GC in the presence of organic alkali. They assigned some branched/cross-linked structure for evolved samples, as well as the xanthone unit $[17],[18]$.

Since there are still inconsistent aspects in the reported work in terms of the polycarbonate degradation mechanism, there has been a lack of ability to confirm the presence of specific functional groups such as carbonate and the products with mass above 228 may not be well-understood. Besides, there is very little work on the degradation behaviour under atmospheric pressure as would be seen in true combustion. Therefore, in order to understand the combustion process, thermogravimetric analysis coupled to infrared spectroscopy, TGA/FTIR, has been used. TGA is a good choice to enable the understanding of degradation in terms of mass loss and the coupling to an FTIR provides the important in situ online data for the identification of the functional groups of the evolved products during polymer degradation ${ }^{[19]}$, but it cannot provide molecular structure information. So, the evolved products were also collected and analysed using FTIR (condensed phase), GC/MS and LC/MS. The samples were collected as a function of mass loss at the different temperatures between 420 and $540{ }^{\circ} \mathrm{C}$.

\section{Experimental}

\subsection{Materials}

PC samples were provided by Cheil Industries Inc. and were used as received; this material is end-capped with $t$ butyl phenol in order to further improve thermal stability. The number and weight average molecular weight of the bisphenol A polycarbonate are 16,000 and 28,000 , respectively.

\subsection{TGA/FTIR analysis and sampling of evolved products}

TGA/FTIR was carried out at a heating rate of $20^{\circ} \mathrm{C} / \mathrm{min}$ under a nitrogen flow of $60 \mathrm{ml} / \mathrm{min}$ on a Cahn TG 131 instrument which was connected to Mattson Research grade FTIR through stainless steel tubing. This instrument uses a sniffer tube that extends into the sample cup to remove the evolved gases; this sniffer tube removes gas at the rate of $40 \mathrm{ml} / \mathrm{min}$. The evolved volatile products are introduced to IR chamber through the sniffer and analysed by FTIR. The temperature reproducibility of the TGA is $\pm 3{ }^{\circ} \mathrm{C}$ and the non-volatile fraction is $\pm 3 \%$. The sample size was $40-60 \mathrm{mg}$.

The evolved products during thermal degradation were collected for 5-20 min as a function of mass loss using a cold trap at a temperature of $-78^{\circ} \mathrm{C}$.

\subsection{Analysis of evolved condensable products at each temperature}

The collected evolved products in the sniffer were washed with acetonitrile. FTIR (Nicolet Magna 560 Model) analysis was performed by placing the material on a $\mathrm{KBr}$ window and allowing the solvent to evaporate. GC/MS spectra were obtained using an Agilent 6850 series GC connected to an Agilent 5973 Series MS ( 70 eV electron ionisation). LC/MS spectra (Electrospray Ionisation, negative) were obtained using an Agilent 1100 Model.

\subsection{FTIR analysis of solid residue sample}

The solid residues at each collection temperature were collected and analysed by FTIR (Nicolet Magna Model 560). 


\section{Results and discussion}

\subsection{Thermal degradation temperature and in situ FTIR results}

The TGA and DTG curves of bisphenol A polycarbonate are shown in Fig. 1. PC shows no weight loss up to $450^{\circ} \mathrm{C}$ and decomposition occurs in a single stage with the maximum rate of degradation around $540{ }^{\circ} \mathrm{C}$, at a heating rate of $20^{\circ} \mathrm{C} / \mathrm{min}$. The char at $700{ }^{\circ} \mathrm{C}$ was $27 \%$. Although there is no noticeable weight loss below $450{ }^{\circ} \mathrm{C}$, a small amount of evolved gases may be detected by FTIR, but no mass loss can be seen by TGA. According to the TGA result, the temperature range of the main degradation is $480-550^{\circ} \mathrm{C}$.

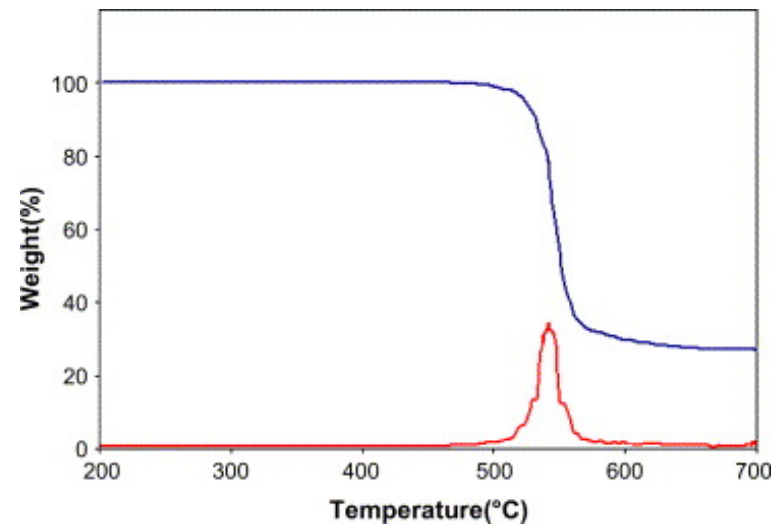

Fig. 1. Thermogravimetric analysis and differential thermogravimetry curves for bisphenol A polycarbonate at a heating rate of $20^{\circ} \mathrm{C} / \mathrm{min}$ under nitrogen.

Fig. 2 shows the in situ FTIR spectra of evolved volatile components at each mass loss. The generation of $\mathrm{CO}_{2}$ and $\mathrm{H}_{2} \mathrm{O}$ were observed over the whole range. In the beginning stage of degradation, the characteristic peaks of an aliphatic substituted phenol were observed. The peaks due to free alcohol, $3645 \mathrm{~cm}^{-1}, \mathrm{sp}^{2}$ carbon-hydrogen and $\mathrm{sp}^{3}$ carbon hydrogen stretching, respectively above and below $3000 \mathrm{~cm}^{-1}$, as well as carbonyl stretching of the carbonate functional group, $1778 \mathrm{~cm}^{-1}$, are observed. The peaks at 1597 and $1500 \mathrm{~cm}^{-1}$ correspond to a ring stretching and skeletal vibration of phenyl compounds.

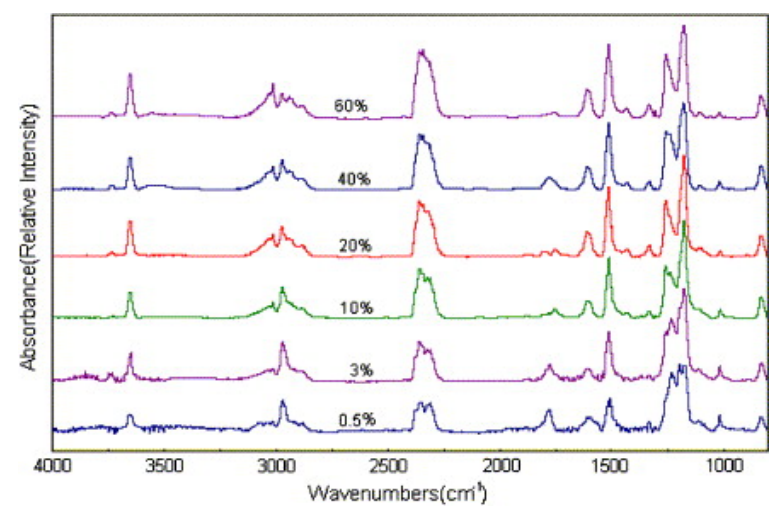

Fig. 2. Vapour phase FTIR spectra for the volatile components at each mass loss.

The bands in the $2800-3200 \mathrm{~cm}^{-1}$ region, which is $\mathrm{C}$ 마 stretching, show quantitative changes as degradation proceeds. Relatively strong $\mathrm{sp}^{3}$ carbon-hydrogen peaks were observed in the lower mass loss, but $\mathrm{sp}^{2} \mathrm{C} \square \mathrm{H}$ stretching bands become the significant peaks at higher mass loss. This implies that more alkyl substituted phenol structures were evolved in the initial degradation stage and phenols having less aliphatic substituents are increased as the decomposition proceeds.

Fig. 3 shows expanded IR spectra between 1300 and $1100 \mathrm{~cm}^{-1}$. The peak at $1260 \mathrm{~cm}^{-1}$ corresponds to aromatic ether stretch, the band at $1238 \mathrm{~cm}^{-1}$ is the $C \Phi$ stretching frequencies of the carbonate linkage, and the 1200 
$\mathrm{cm}^{-1}$ band corresponds to isopropylidene vibrations of polycarbonate [20]. The peak at $1174 \mathrm{~cm}^{-1}$ is the carbonhydroxy stretching band.

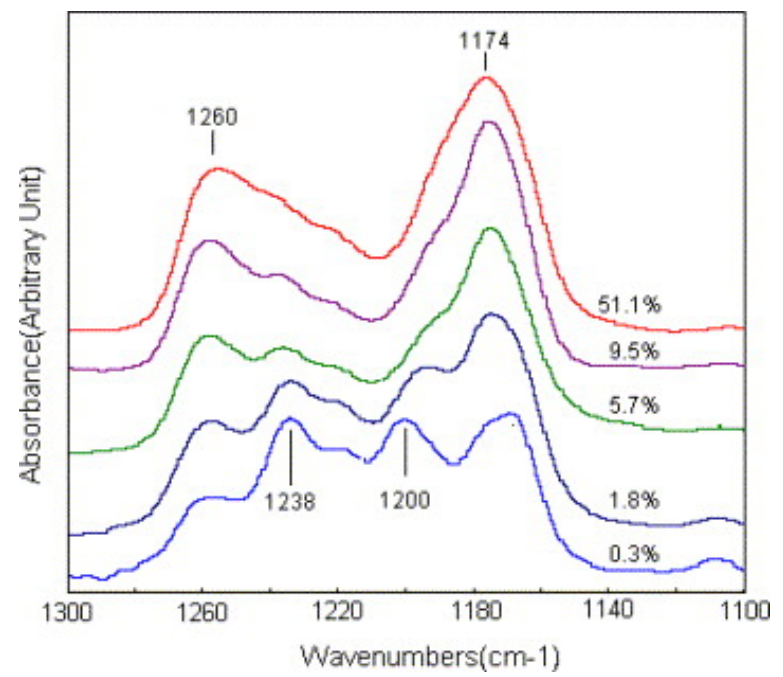

Fig. 3. The expanded FTIR spectra as a function of mass loss of polycarbonate.

As mass loss increases, it can be seen that the $1238 \mathrm{~cm}^{-1}$ and 1200 bands decrease and the $1174 \mathrm{~cm}^{-1}$ band significantly increases. This suggests that the compounds having aliphatic substituted phenol or carbonate functional group evolve in the initial mass loss region and the structures having more alcohol functional groups are generated as mass loss proceeds. The spectra at $9.5 \%$ weight loss is similar to that at $51.1 \%$ weight loss, which suggests that there is not a large difference in the functional groups that are evolved in this region; this is also supported by Fig. 2.

In the main mass loss region, which is $480-520^{\circ} \mathrm{C}$, most of the peak positions and relative intensities are the same, except in the $\mathrm{C} \square \mathrm{H}$ stretching region. This suggests that the degraded materials are not qualitatively different in terms of functional groups.

\subsection{Analysis of collected products evolved at each mass loss}

The condensed phase FTIR spectra for the products are shown in Fig. 4. Again, there is no qualitative difference in terms of functional groups that are observed. In the case of condensed phase FTIR, since there are strong hydrogen bonds due to high concentration of various products having hydroxyl groups, the alcohol stretching bands become broad and the carbonate characteristic band, $1778 \mathrm{~cm}^{-1}$, is shifted to $1750 \mathrm{~cm}^{-1}$. This may be attributed to hydrogen bonding between the carbonate moiety and alcohols. As shown in vapour phase FTIR, relatively strong $\mathrm{sp}^{2}$ carbon-hydrogen stretching bands are observed in the higher mass loss region. FTIR spectra suggest that there are considerable amounts of alcohol and carbonate group in the evolved products over the whole range. Montaudo et al. identified the xanthone skeleton as one of main products of degradation [10], [11], [12], [13], [14], [15], [16]; by infrared spectroscopy of the evolved products, there is not sufficient evidence for the formation of xanthone, i.e. the characteristic carbonyl peak $\stackrel{[21]}{\text { of } x a n t h o n e}$ at around 1660 $\mathrm{cm}^{-1}$ is not observed. 


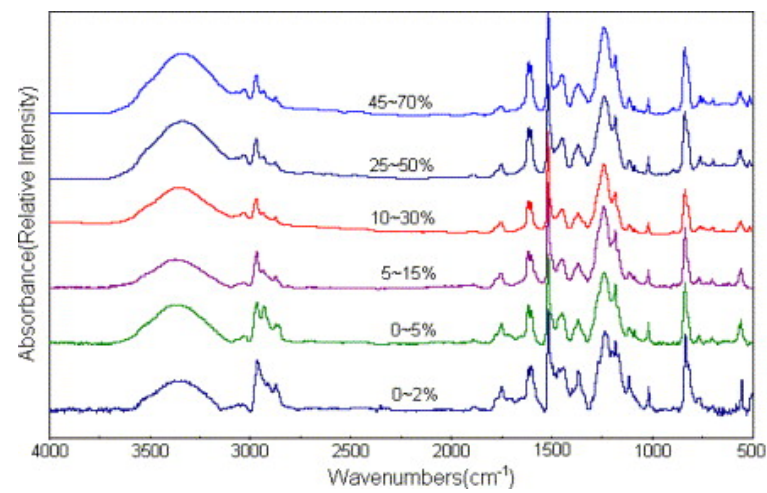

Fig. 4. Condensed phase FTIR spectra of collected evolved products at each mass loss.

The band at $830 \mathrm{~cm}^{-1}$ corresponds to the aromatic carbon-hydrogen out-of-plane vibration, which implies that evolved products over the whole range are mainly para disubstituted aromatic compounds. The band at 1880 $\mathrm{cm}^{-1}$, corresponding to overtone and combinations due to out-of-plane deformation vibrations, supports this.

In order to provide an opportunity for the identification of components in the evolved products, both GC/MS and LC/MS were used; the strategy that was followed was to use GC/MS for lower molecular weights, using the MS fragmentation pattern and functionality information from FTIR, and to reserve LC/MS for higher molecular weights.

The GC traces, as a function of mass loss at which the sample was collected, shown in Fig. 5 , have appended the molecular weights that have been discerned, and the corresponding structures, having one or two benzene rings, are shown in Table 1. For the products having one or two benzene rings, all evolved products are mainly classified into three groups, which are phenols, ethers and carbonates.

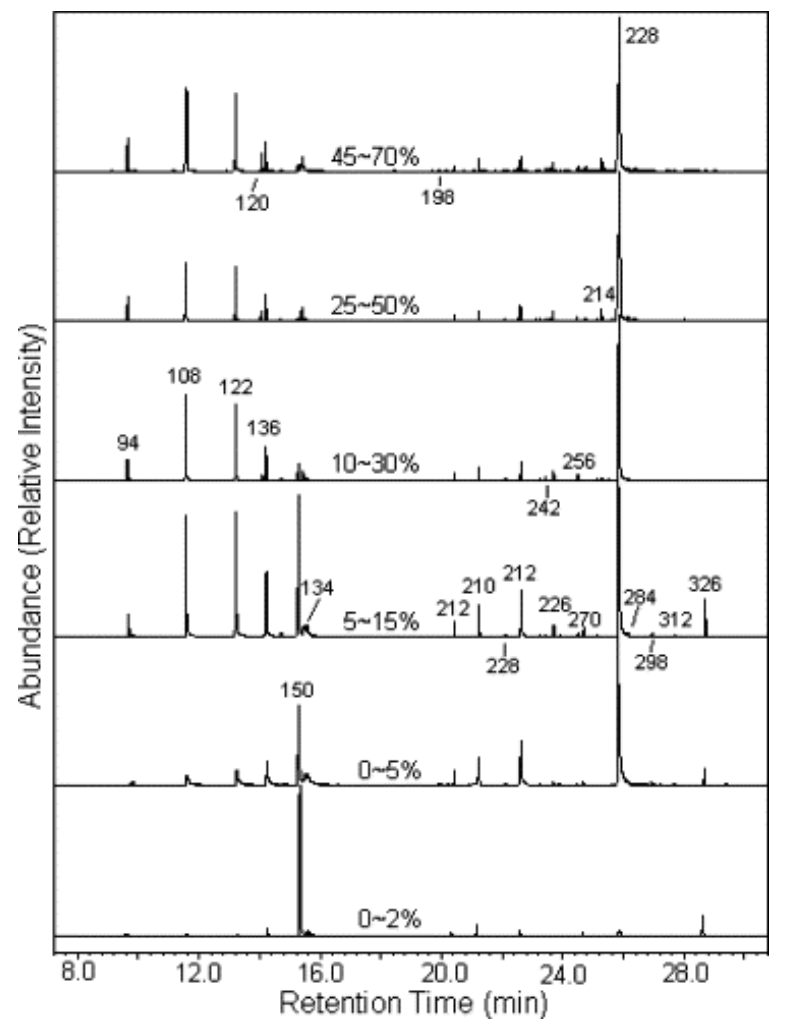

Fig. 5. GC traces of the evolved decomposition products. Inset numbers on each peak indicate the molecular weight acquired by mass spectroscopy and percentages denote the mass loss range for the collected sample. 
Table 1. Assigned structures having one and two benzene rings from GC/MS results

\begin{tabular}{|c|c|}
\hline Group & Structures $(\mathrm{m} / \mathrm{z}$, retention time in minutes) \\
\hline Alcohols & 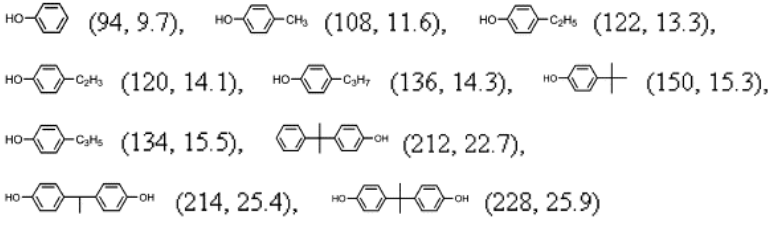 \\
\hline Ethers & 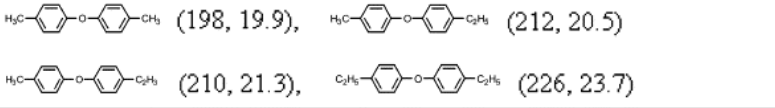 \\
\hline Carbonates & 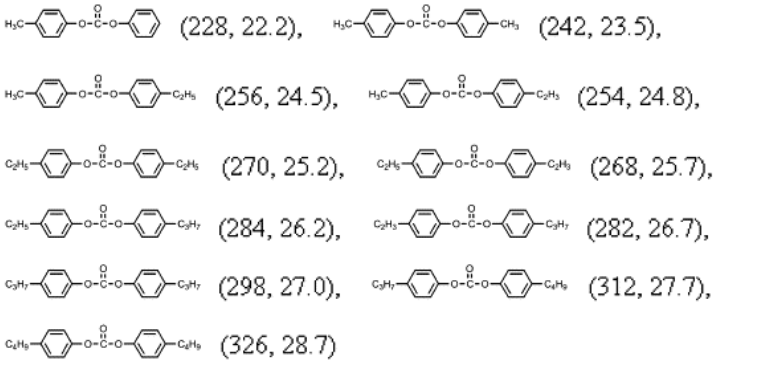 \\
\hline
\end{tabular}

In the beginning degradation stage, $0-2 \%$ mass loss, the evolution of $t$-butyl phenol $(\mathrm{m} / \mathrm{z} 150,15.3 \mathrm{~min}$ retention time), which has been used to cap the end of polycarbonate chain, and $\mathrm{m} / \mathrm{z} 326$ (28.7 $\mathrm{min})$, bis( $t$-butyl phenyl)carbonate, were noted, which means scission at the chain-ends of polycarbonate. The ether compounds, $\mathrm{m} / \mathrm{z} 212$ (20.5 $\mathrm{min}$ ) and $\mathrm{m} / \mathrm{z} 210$ (21.3 $\mathrm{min}$ ) are also assigned, which implies rearrangement of the carbonate linkage. In this region, bisphenol $\mathrm{A}$ is not an important evolved product.

As the mass loss increases, more alcohol compounds, such as phenol (9.7 min retention time), $p$-methyl phenol (11.6 min), $p$-ethyl phenol (13.3 min), $p$-isopropyl phenol (14.3 min) and bisphenol A (25.9 min), become important evolved products through the end stage of degradation, due to chain scission along the weak bonds and alcoholysis/hydrolysis of carbonate linkages. Except in the initiation region, the products are not qualitatively different. The products having carbonate linkage, $\mathrm{m} / \mathrm{z} 228$ (22.2 min), 242 (23.5 min), 256 (24.5 $\mathrm{min}), 270$ ( $25.2 \mathrm{~min}), 284$ ( $26.2 \mathrm{~min}$ ), etc., which have not been detected by previous workers [4], [5], [6], [7], [8], [9], [10], [11], [12], [13], [14], [15], [16], [17], [18], are observed in significant amounts, as expected from the FTIR results. This supports the idea that chain scission of the isopropylidene linkage is one of the main degradation pathways. A very interesting peak is observed at a retention time of $25.4 \mathrm{~min}(\mathrm{~m} / \mathrm{z} 214)$ in the main mass loss region and it is assigned as 1,1'-bis(4-hydroxyphenyl) ethane from its fragmentation pattern. This implies that methyl scission occurred in the isopropylidene linkage of polycarbonate. The mass spectrum of structures having isopropylidene linkage shows that methyl scissions occur easily; Wiley et al. studied the fragmentation pattern of the polycarbonate dimer using MS and showed fragmentation patterns which correlate with the loss of methyl groups and carbon dioxide ${ }^{[22]}$. The bond dissociation energies of polycarbonate are shown in Fig. $6^{[4],}$ [23] . It is clear that the $C \square \mathbb{C}$ bond dissociation of the isopropylidene linkage is easiest, followed by $\mathrm{C} \Phi$ scission of carbonate group. However, the carbonate group is reactive to alcohol and water, so the degradation may not exactly follow the bond dissociation energies. 


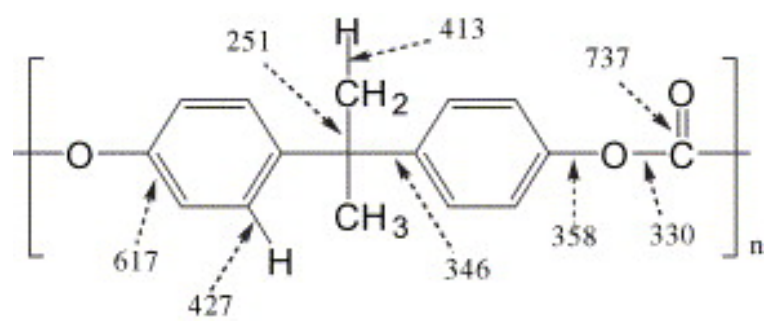

Fig. 6. Bond dissociation energy of bisphenol A polycarbonate in $\mathrm{kJ} / \mathrm{mol}$ [4], [23].

Fig. 7 shows the high molecular weight from GC/MS, since GC/MS is not sensitive to large molecules, relatively weak peaks were observed. The assigned structures mostly correspond to the structures having three benzene rings. (Table 2) Again, most structures correspond to either ethers or carbonates.

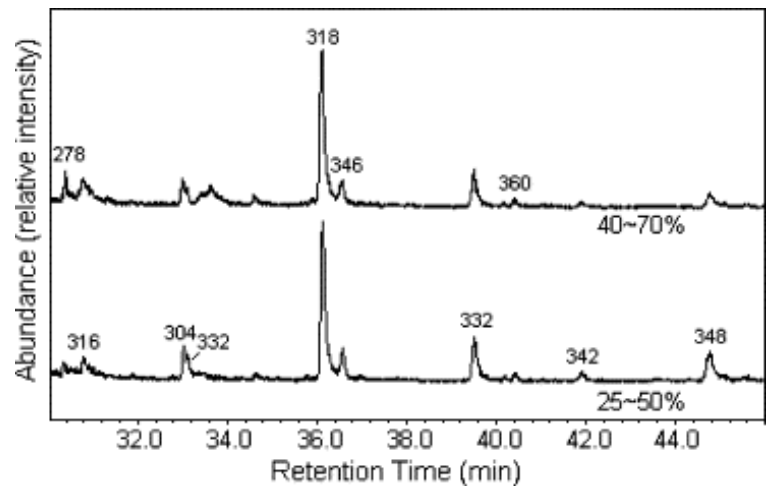

Fig. 7. Expanded GC data for higher retention time up to $46 \mathrm{~min}$.

Table 2. The structures having some three benzene rings in GC/MS results of Fig. 7

\begin{tabular}{|c|c|}
\hline Linkage & Structures $(\mathrm{m} / \mathrm{z}$, retention time in minutes) \\
\hline Ethers & 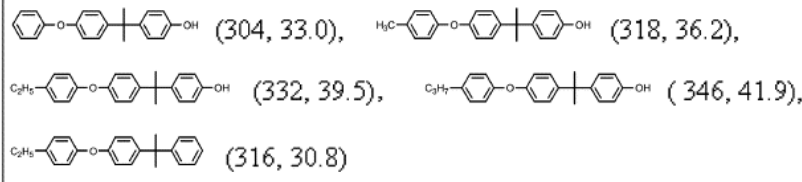 \\
\hline Carbonates & 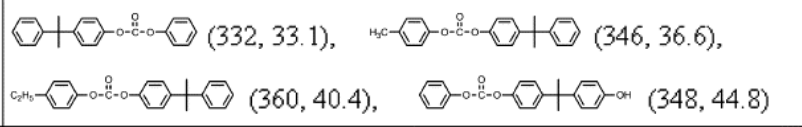 \\
\hline
\end{tabular}

From the above FTIR and GC/MS results, alcohols, ethers and carbonates are mainly detected and assigned over the whole mass loss range. It appears that other functional groups such as xanthone, furan, and ketone [10], [11], [12], [13], [14], [15], [16] are not significant in the evolved products during thermal degradation of polycarbonate under nitrogen at atmospheric pressure.

While the assignment of structures for GC/MS data is fairly easy and clear through fragmentation pattern, it is much more difficult to assign molecular weights for the large species that are obtained by LC/MS (Fig. 8), which covers the molecular weight range, 250-800, because LC/MS does not provide a fragmentation pattern and there is an increased possibility for the formation of a variety of isomers, due to the greater complexity of the molecules. In order to assign the significant peaks for high molecular weights in LC/MS data, several postulates were developed based upon the data of GC/MS and FTIR. First, the possibility of unsaturated aliphatic end groups was discarded. If one compares the GC peaks of Fig. 5 at 13.3 and $14.3 \mathrm{~min}(\mathrm{~m} / \mathrm{z} 122$ and 136, respectively), which have alkyl end groups, with 14.1 and $15.5 \mathrm{~min}$ (m/z 120 and 134, respectively), with alkenyl 
end groups, the former are much more intense and one can simplify the process by ignoring unsaturated end groups. Second, according to the bond dissociation energies of Fig. 6 , the abundance of products having methyl or ethyl substituents on the benzene ring is larger than those with hydrogen or isopropyl. The relative intensities of phenol (9.7 min), $p$-methylphenol (11.6 min), p-ethylphenol (13.3 $\mathrm{min}$ ) and $p$-isopropylphenol (14.3 $\mathrm{min})$ explain this, as shown in Fig. 5. Third, all benzene rings are paradisubstituted based on FTIR data; if one substituent is hydrogen or alkyl, the other is either hydrogen or oxygen-containing. Fourth, in those cases where the assignment is very difficult or a linear structure seems unlikely, cross-linked structures based on 1,1-bis(4hydroxyphenyl)ethane were considered.

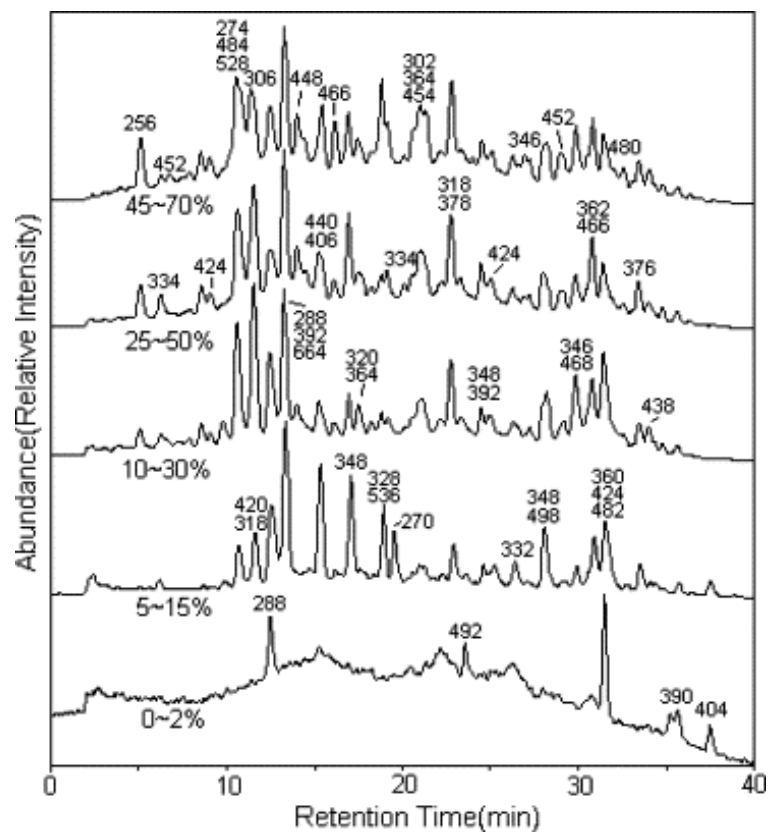

Fig. 8. LC spectra of evolved condensed products. Inset numbers indicate the molecular weight acquired by mass spectroscopy.

Based on the above postulates and GC/MS results, the significant molecular ion peaks of the LC of Fig. 8 for the evolved products were assigned, as shown in Table 3. For the structures having two or three benzene rings, structures that have already been assigned by GC/MS are not shown here. In general, mainly ether or carbonate structures were identified, as also seen for lower molecular weight species. In the structures having four benzene rings, those with ether and carbonate linkages have molecular weights of 424 ( $25.3 \mathrm{~min}$ ), 438 (27.5 $\mathrm{min}$ ), 452 (29.0 $\mathrm{min}), 466$ (30.6 $\mathrm{min}$ ) and 480 (32.8 $\mathrm{min})$. It is interesting for the structures having four benzene rings that species that contain both a carbonate and an ether are observed but there are no species which contain more than one carbonate or more than one ether linkage. It can be speculated that the carbonate groups undergo rearrangement [5], [8], [17] in a random fashion followed by decarboxylation or cross-linking upon heating as shown in Scheme 2; if consecutive carbonate linkages undergo rearrangements, then it is likely to give cross-link structures and, eventually, char. So, it could be thought that this reaction scheme is the source of $\mathrm{H}_{2} \mathrm{O}$ and $\mathrm{CO}_{2}$ evolution during the entire mass loss range, as observed in the TGA/FTIR study.

Table 3. Structure assignments for the significant peaks in LC/MS 


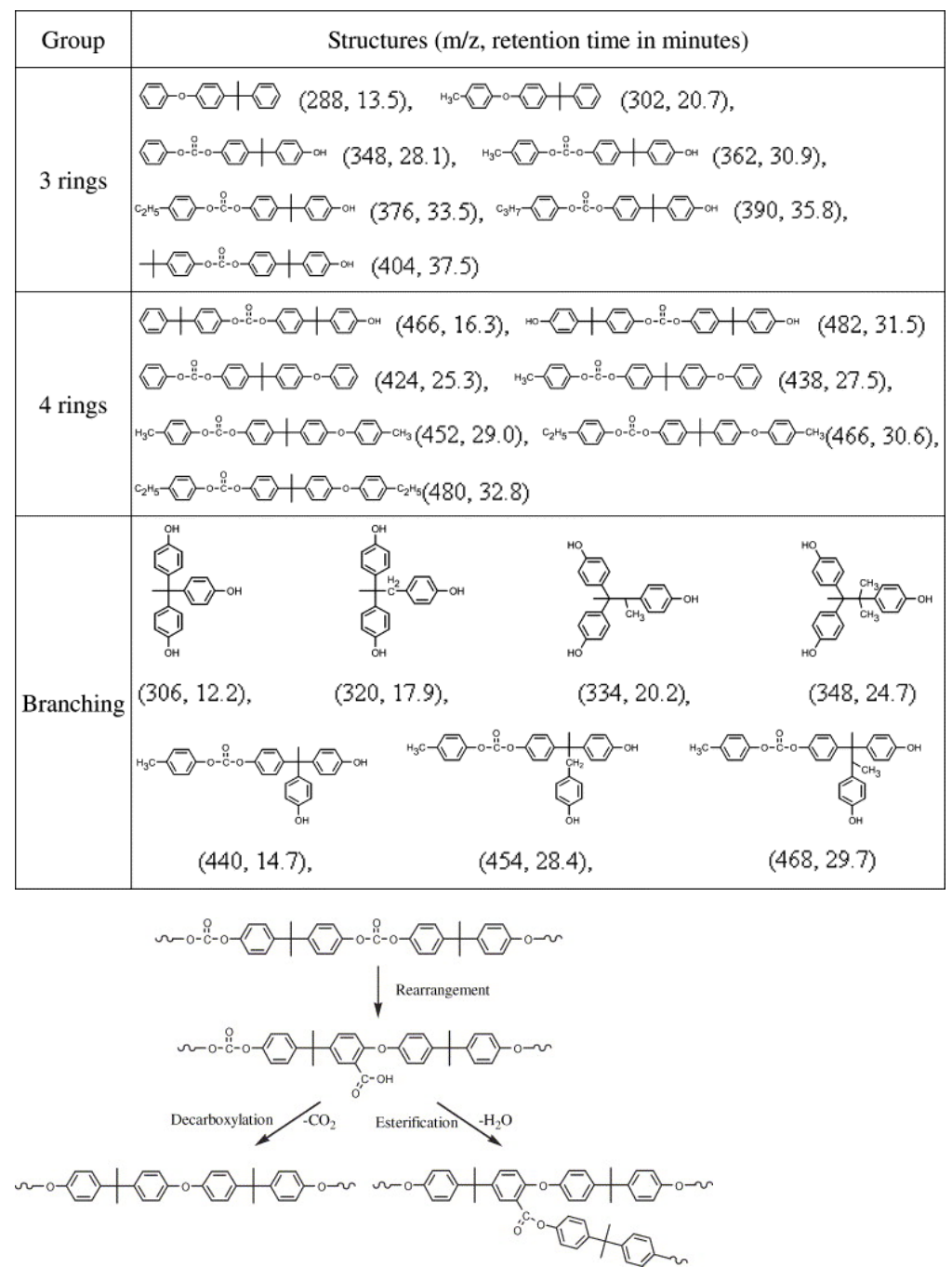

Scheme 2 .

In addition to linear structures, branched molecules, which may occur by radical recombination reactions, are shown in Table 3. Since there is no fragmentation pattern available, these are speculative structures based on chain scission, according to the bond dissociation energy and the abundance of other identified products. From the bond dissociation energy, the methyl scission of isopropylidene linkage is easiest. So, it is very possible to have recombination reactions between two aliphatic radicals, as shown in Scheme 6.

\subsection{FTIR analysis of solid residue samples}

FTIR spectra for the solid residues are shown in Fig. 9. Similar to vapour phase FTIR of the evolved products, as the mass loss at which the material is collected increases, the $\mathrm{sp}^{2}$ carbon hydrogen peak increases in terms of relative intensity. Below $30 \%$ mass loss, the absorbance and position of the FTIR peaks are qualitatively the same and the spectrum is much more complicated than that of virgin PC. This suggests that there might be rearrangements of polycarbonate in this regime. Above $30 \%$ mass loss, as the mass loss increases, the solid residues become more char-like. The alcoholic peaks are observed over the whole mass loss range, while the characteristic peak of carbonate, $1780 \mathrm{~cm}^{-1}$, could be observed up to $50 \%$ mass loss and then disappeared at $70 \%$ mass loss. Also, the characteristic ester band at $1740 \mathrm{~cm}^{-1}$ can be observed as a shoulder. 


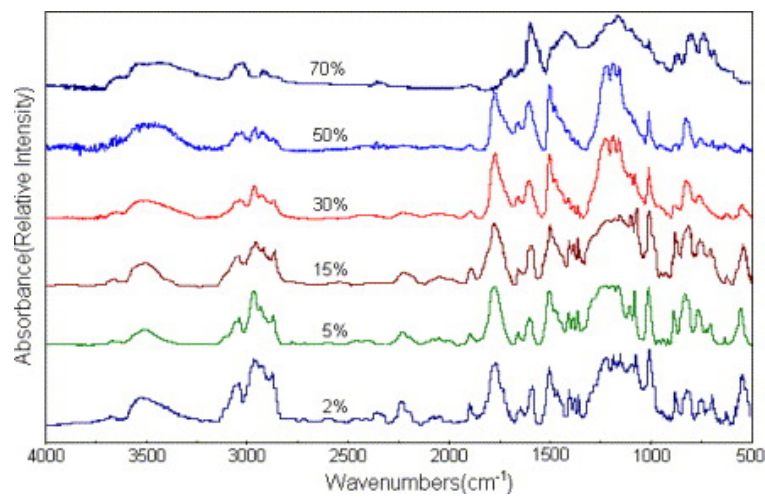

Fig. 9. Condensed phase FTIR spectra of solid residue samples at each collecting temperature.

\subsection{Degradation pathways of bisphenol A polycarbonate}

From the above results, the major thermal degradation pathways for bisphenol A polycarbonate are derived and these are shown in Scheme $2, \underline{\text { Scheme } 3}$, Scheme 4 Scheme 5 , Scheme 6.

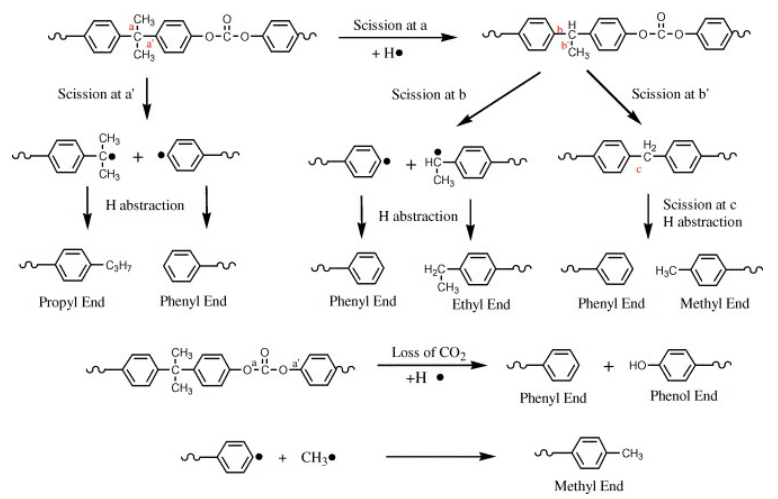

Scheme 3.

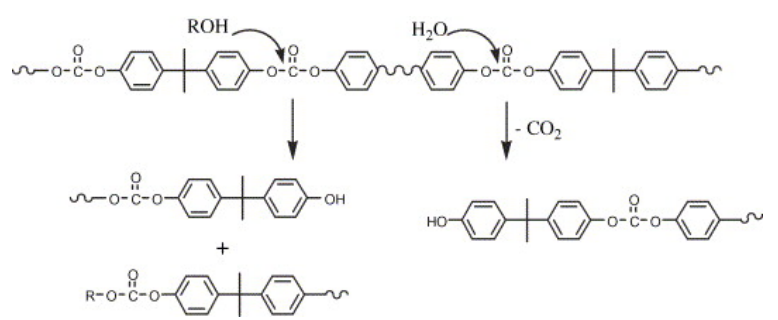

Scheme 4.

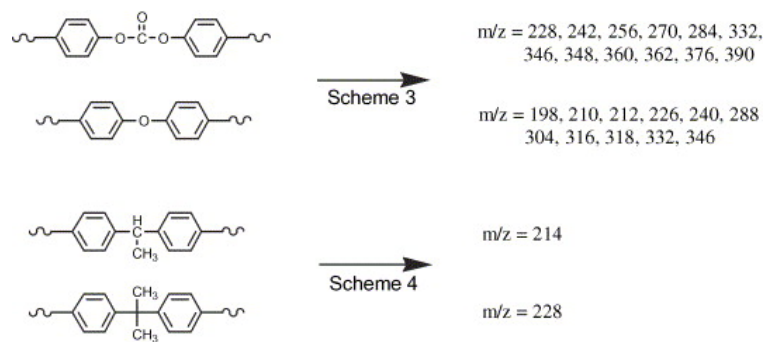

Scheme 5 . 


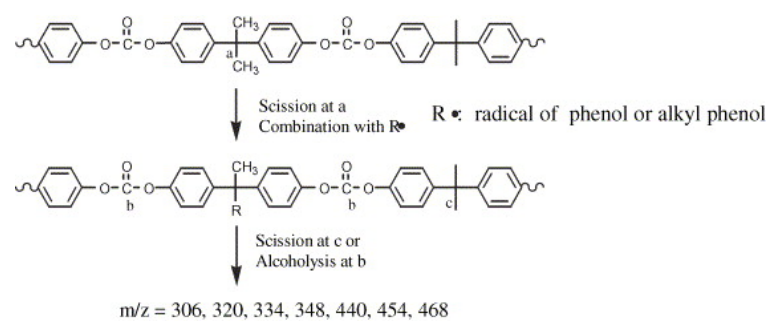

Scheme 6.

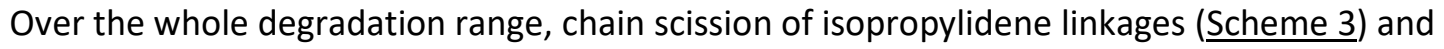
alcoholysis/hydrolysis of carbonate linkages (Scheme 4 ) are the main degradation pathways. Thus, alcohol end groups are mainly caused by alcoholysis/hydrolysis of carbonate linkages, while phenyl or aliphatic end groups are primarily produced due to chain scission. Lee and McNeill et al. [4], 99] proposed that the hydrogen scission or isopropylidene scission occur first. However, through the assignment and relative abundance for each evolved product, it appears that methyl scission of the isopropylidene linkage occurs first, in accordance with the bond dissociation energies. This illustrates why the relative abundances of methyl or ethyl end groups are more intense than those of phenyl or isopropyl end groups. At the beginning of degradation, rearrangement of some

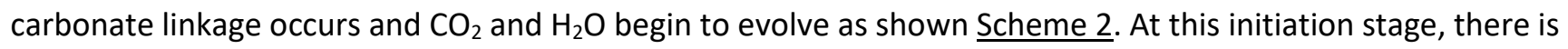
no significant mass loss. Through the GC/MS and FTIR results, the significant evolved compounds are found to be compounds having a $p$-t-butyl phenol chain end, due to chain scission. As mass loss increases, more alcohols are produced and then these alcohols act as the source of alcoholysis which is the pathway for the evolution of bisphenol A.

In the main mass loss region, the abundant evolved products are phenol, $p$-methyl phenol, $p$-ethyl phenol, $p$ isopropyl phenol and bisphenol A. Except for these lower molecular weight alcohols, most assigned structures can be classified as either ethers or carbonates. Scheme 5 shows how the materials that are formed in $\underline{\text { Scheme }}$ $\underline{2}$ can produce the various products that result from the Scheme 3 , Scheme 4 . With regard to cyclic carbonate oligomers ${ }^{[9]},[15]$ of which molecular weights are 508 and 762, although both Montaudo and McNeill proposed schemes for cyclic oligomers [9], [10], [11], we were not able to obtain sufficient data for these cyclic compounds through this study on the degradation of polycarbonates of which ends are capped with $t$-butyl phenol.

As shown in Scheme 5, the presence of 1,1'-bis(4-hydroxyphenyl)ethane and the large number of carbonate structures that are observed leads to the suggestion that one of the main degradation pathways is the chain scission of isopropylidene linkages.

In the case of branched structures, the 1,1'-diphenylethane skeleton is closely related to the branched structures. The radical of $1,1^{\prime}$-diphenylethane produced via methyl scission is quite stable, so it is very probable to react with another radical, such as para aliphatic substituted phenol radicals in the condensed phase of degrading polycarbonate, as shown in $\underline{\text { Scheme } 6 .}$.

\section{Conclusion}

Through the use of TGA/FTIR and chromatography coupled with mass spectrometry, the significant evolved products have been identified. The main degradation pathways of polycarbonate, end-capped with $t$ butylphenol, are classified into two categories; chain scission of isopropylidene linkages and hydrolysis/alcoholysis of carbonate linkages. It must be noted that different end caps on the PC may give rise to different degradation pathways and thus to different products. According to the bond dissociation energies, methyl scission occurs primarily and many of these linkages undergo further chain scission, while some react with alkyl substituted phenol radicals and form branched structures. The hydrolysis/alcoholysis of carbonate linkage produces alcohol products. Some carbonate linkages undergo rearrangement which forms ether linkage. 
Or it is speculated that some of them react with alcohol end groups, eventually to form char like structures. The presence of bisphenol A in a large intensity implies that hydrolysis/alcoholysis of carbonate linkage is the pathway for the formation of that compound. The presence of carbonate structures and 1,1'-bis(4-hydroxyl phenyl) ethane supports the view that chain scission is one of main degradation pathways.

\section{Acknowledgements}

We gratefully acknowledge the help of Ms Marylin Isbell and Dr Kasem Nithipaticom of the Department of Pharmacology and Toxicology, Medical College of Wisconsin, for assistance in the analysis of the LC/MS data.

\section{References}

[1] D.W. van Krevelen. Polymer, 16 (1975), p. 615

[2] J. Green. J Fire Sci, 9 (1991), p. 285

[3] J. Green. J Fire Sci, 12 (1994), p. 388

[4] L.H. Lee. J Polym Sci, 2 (1964), p. 2859

[5] A. Davis, J.H. Golden. J Gas Chromatogr, 5 (1967), p. 81

[6] A. Davis, J.H. Golden. Macromol Chem, 110 (1967), p. 180

[7] A. Davis, J.H. Golden. J Macromeol Sci Rev Macromol Chem, C3 (1968), p. 49

[8] I.C. McNeill, A. Rincon. Polym Degrad Stab, 39 (1993), p. 13

[9] I.C. McNeill, A. Rincon. Polym Degrad Stab, 31 (1991), p. 163

[10] A. Ballistreri, G. Montaudo, C. Puglisi, E. Scamporrino, D. Vitalini, S. Cucinella. J Polym Sci Polym Chem Ed, 26 (1988), p. 2113

[11]G. Montaudo, C. Puglisi. Polym Degrad Stab, 37 (1992), p. 91

[12] C. Puglisi, L. Sturiale, G. Montaudo. Macromolecules, 32 (1999), p. 2194

[13] C. Puglisi, F. Samperi, S. Carroccio, G. Montaudo. Macromolecules, 32 (1999), p. 8821

[14] S. Carroccio, C. Puglisi, G. Montaudo. Macromolecules, 35 (2002), p. 4297

[15] G. Montaudo, S. Carroccio, C. Puglisi. Polym Degrad Stab, 77 (2002), p. 137

[16] G. Montaudo, S. Carroccio, C. Puglish. J Anal Appl Pyrolysis, 64 (2002), p. 229

[17] K. Oba, Y. Ishida, Y. Ito, H. Ohtani, S. Tsuge. Macromolecules, 33 (2000), p. 8173

[18] K. Oba, H. Ohtani, S. Tsuge. Polym Degrad Stab, 74 (2001), p. 171

[19] M.L. Mittleman, D. Johnson, C.A. Wilkie. Trends Polym Sci, 2 (1994), p. 391

[20] A.S. Politou, C. Morterra, M.J.D. Low. Carbon, 28 (1990), p. 529

[21] C.J. Pouchert. The Aldrich library of FT-IR spectra, vol. 2, Aldrich Chemical Company (1985) p. 92

[22] R.H. Wiley. Macromolecules, 4 (1970), p. 254

[23] X. Li, M. Huang. Polym Int, 48 (1999), p. 387 